\title{
The Research of New Type Hydraulic Breaker with Strike Energy and Frequency of Adjusted
}

\author{
Guoping Yang ${ }^{1} \&$ Yubao Chen $^{2}$ \\ ${ }^{1}$ College of Automotive Engineering, Shanghai University of Engineering and Science, Shanghai, China \\ ${ }^{2}$ Department of Industrial and Manufacture System Engineering, University of Michigan-Dearborn, Dearborn, \\ USA \\ Correspondence: Guoping Yang, College of Automotive Engineering, Shanghai University of Engineering and \\ Science, Shanghai, ON., 201620, China. Tel: 86-021-5217-8766. E-mail: ygpljyl@163.com
}

Received: July 2, 2012 Accepted: July 23, 2012 Online Published: August 15, 2012

doi:10.5539/mer.v2n2p45 URL: http://dx.doi.org/10.5539/mer.v2n2p45

\begin{abstract}
After analyzing the technology of hydraulic breaker at home and abroad, this paper challenges tradition and develops a new full hydraulic pressure hydraulic breaker with strike energy and frequency adjusted steplessly and independently, and discuss its working principle, structural feature and hydraulic system, analyses its technical properties and presents experiment results. With all the achievements mentioned above, it establishes technology foundation for the development of hydraulic breaker.
\end{abstract}

Keywords: hydraulic breaker, compact equipment, full hydraulic, strike energy and frequency adjusted independently, pressure feedback

\section{Introducation}

Along with the development of hydraulic pressure technology, the hydraulic punching machines are more and more widely used in different industries of the society. It has formed an important new technical industry overseas. Compared with the advanced foreign countries, at present there is still a larger gap on the aspect of research and production of the hydraulic punching machines in China. As everyone knows, the output of the hydraulic punching machine is impact energy (E) and frequency (f). With the reasonable matching of the two parameters, the machine can suit different working conditions bringing the best working effect, thereby advancing productivity and reducing cost and enlarging its application scope. Therefore, the technical performance parameters (E \& f) of modern hydraulic punching machine should be independently and steplessly adjustable. The technical performance of the hydraulic punching machine depends on its operation mechanism hydraulic breaker. Based on analyzing the present hydraulic breakers at home and abroad, this article brings forward a new full hydraulic type breaker with strike energy and frequency adjusted independently.

\section{Full Hydraulic Type Breaker with Strike Energy and Frequency Adjusted Independently}

\subsection{Basic Configuration}

It mainly consists of chisel lever (1), piston (2), frame (3), pilot type orifice valve (4), accumulator (5) and so on. See Figure 1 for its configuration. 


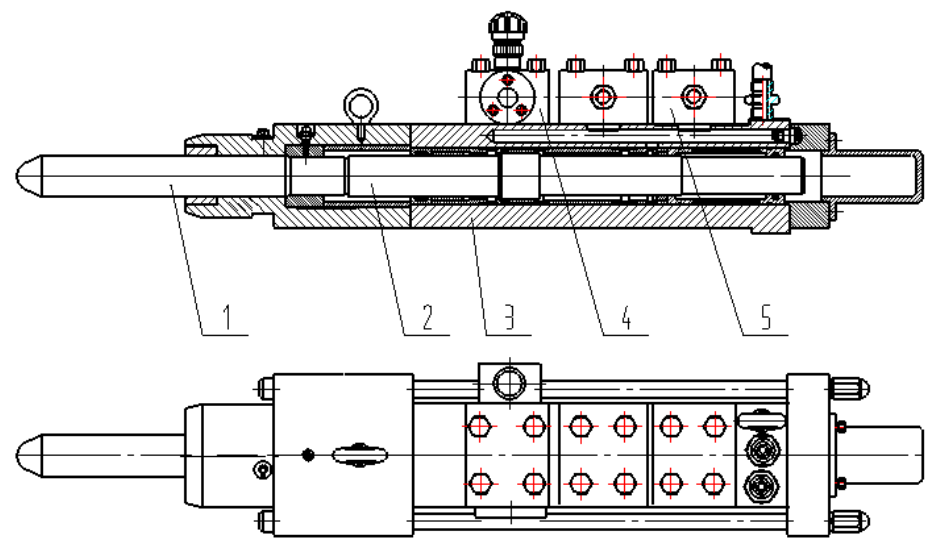

1-chisel lever, 2-piston, 3-frame, 4-pilot type orifice valve, 5-accumulator

Figure 1. Structure of the pressure feedback hydraulic breaker

\subsection{Working Principle}

The new hydraulic breaker takes advantage of the pressure feedback control principle, which breaks through the traditional principle of stroke feedback control. It also breaks the linkage relationship between Pd and Qd, realizing the independent stepless adjustment of working pressure and oil flow, therefore reaching the purpose of high efficiency and energy-saving.

See the Figure 2 for the working principle of the full hydraulic type breaker with independent frequency and strike energy regulating. Of them, the hydraulic breaker is of pressure feedback type. The HD is pressure changing pump, its output is in direct proportion to its control pressure. If only changing the control pressure PK, then we can change the output of the pump. The JF is a pilot valve and its deferent control pressure PK, Px is in direct proportion to the rotating angle which controls the handle. The WH is a hydraulic two-position four-way valve for controlling the opening and stop of the hydraulic breaker. The DR is a pressure reducing valve for reducing the oil pressure in the main oil route to suit the application of the control loop.

After startup of the system, the HD pump is under the state of unloading, here the output of pump is the minimum and it unloads through the overflow valve. Meanwhile, through the pressure reducing valve DR the control loop has built the working oil source for standby.

To operate the hydraulic breaker, just move the handle of JF pilot valve. While turning the handle to the left, the left automatic pressure reducing valve works, export the control oil pressure $\mathrm{P}_{\mathrm{K}}$ to the oil pump and the WH reversing valve. Under the action of $\mathrm{P}_{\mathrm{K}}$, the WH is located in the left and the pressure oil Pd connects with the breaker going into operation. The work of the pressure feedback hydraulic breaker is implemented by back stroke and stroke of its piston.

- Back stroke (See Figure 2 for the starting position of the piston and the valve core of reversing valve)

Under the action of the spring force of the reversing valve, the starting position of the valve core of the reversing valve is located in the left, here the high pressure oil enters into the front and back cavity at the same time. Since the effective operation area in the front cavity is larger than that in the back cavity, the piston moves to the right under the action of pressure difference between the front and back cavity, then the high pressure accumulator is filled with oil, therefore the working pressure of the system goes up. With the system pressure going up and becoming larger than the control pressure of the pilot valve (this pressure is determined by the oil pressure Px of the control oil route and adjusted by motorman according to the actual working situation), the pilot valve opens, and the high pressure oil reflows to oil box through the center damp orifice of the reversing valve and the pilot valve. Here, due to the high pressure oil passes the center damp orifice of the reversing valve, the two ends of the reversing valve produce pressure difference and the effective operation areas of the two ends of the reversing valve are equal. With the action force from the pressure difference larger than the spring force of the reversing valve, the reversing valve changes the direction, letting the reversing valve is located in the right and the breaker shifts to the stroke.

- Stroke

After the valve core of the reversing valve being located in the right (Figure 2 is not indicated), the front cavity 
of the piston connects through with the oil box and under the actions of the high pressure oil of the back cavity and the ejecting oil from the high pressure accumulator, the piston accelerates to move to the left for implementing the stroke. A part of the pressure oil in the front cavity enters into the oil storage cavity through the channel in the frame and the other part of the oil reflows to the oil box. In the stroke acceleration later stage, the system pressure reduces and the pilot valve closes. Under the spring force of the reversing valve, the reversing valve resets. At the same time, the piston impacts the chisel lever, the stoke ends and the system is located again at the state shown by the Figure 2 preparing for a new cycle. The output of oil pump HD varies along with the big and small of $\mathrm{P}_{\mathrm{K}}$. With rotating angle of the handle turning wider, the $\mathrm{P}_{\mathrm{K}}$ and output of the pump turns larger too. Therefore, through control of the JF handle rotating angle, it is easy to control the output of the pump - to control the frequency of (f) the hydraulic breaker. When the handle turns to the right, the automatic pressure reducing valve in the right works and exports the control oil $\mathrm{P}_{\mathrm{X}}$ to the hydraulic breaker. The working pressure $\mathrm{Pd}$ of the hydraulic breaker changes along with the amount of the $\mathrm{P}_{\mathrm{X}}$. The more the handle is rotated, the more the Pd and the output impact energy of the hydraulic breaker are. Thereby, the impact energy (E) of the hydraulic breaker can be controlled through adjusting the rotating angle of the JF handle, i.e., a JF handle can at the same time control two output parameters of the hydraulic breaker.

Since the handle rotating angle of the JF pilot valve can implement stepless-turning, the output of the hydraulic breaker can also implement stepless adjustment. Since the installed capacity of the hydraulic breaker in use is fixed, if high impact energy is required for a hard-operation workpiece, the JF handle can be turned front right $45^{\circ}$, then the working situation of large impact energy and lower frequency can be obtained. It can effectively meet the operation requirement of high impact energy and can also avoid the overload of the system. When a workpiece needs smaller impact energy, the JF handle can be turned front left $45^{\circ}$, then the working situation of small impact energy and high frequency can be obtained so as to improve the work efficiency.

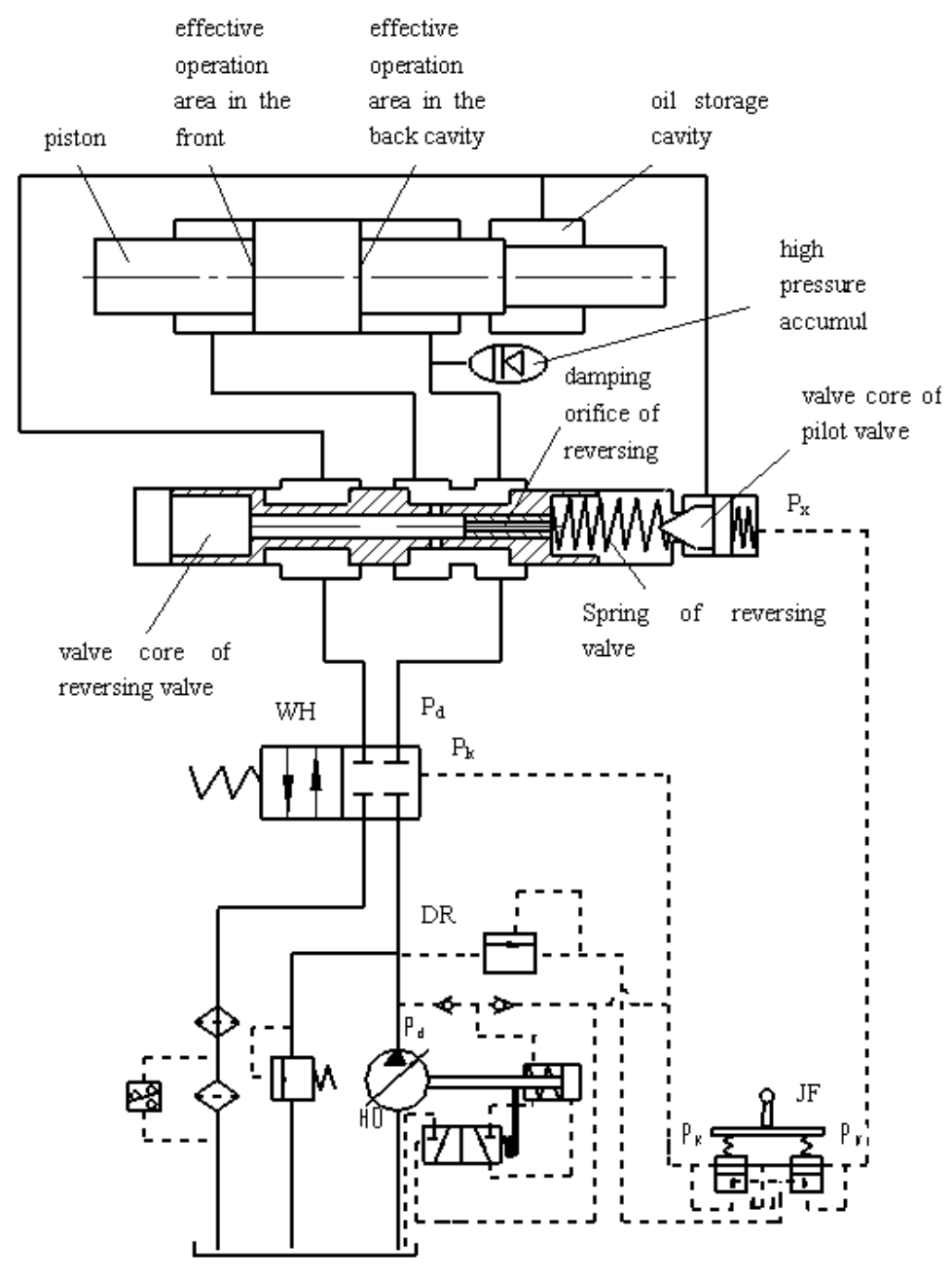

Figure 2. Experiment model photograph of the pressure feedback hydraulic breaker 
Obviously, the above description is the unique technical functions of the hydraulic breaker with full hydraulic independent frequency and strike energy regulating. Compared with the common hydraulic breaker, it can export more impact energy under the same installed capacity and can extend the application scope of the machine. A motorman can reasonably choose the best combination between impact energy (E) and frequency (f) according the actual working situation on the construction scene guaranteeing the best working state of the hydraulic breaker realizing an operation with high efficiency and energy-saving.

\section{Experimental Model Machine Test}

We developed a experimental model machine in accordance with the principle of pressure feedback control, It is mainly composed of hydraulic breaker, pressure sensor, Speed Sensor, PC6313 Data Acquisition Card, computer, Promoting hydraulic cylinder, bearing bracket and impact objects. See Figure 3 for details, Where $P_{d}$ is the hydraulic breaker system pressure, $\mathrm{P}_{\mathrm{T}}$ is advancing hydraulic cylinder pressure in the system, $\mathrm{P} 0$ is back to the oil pressure.
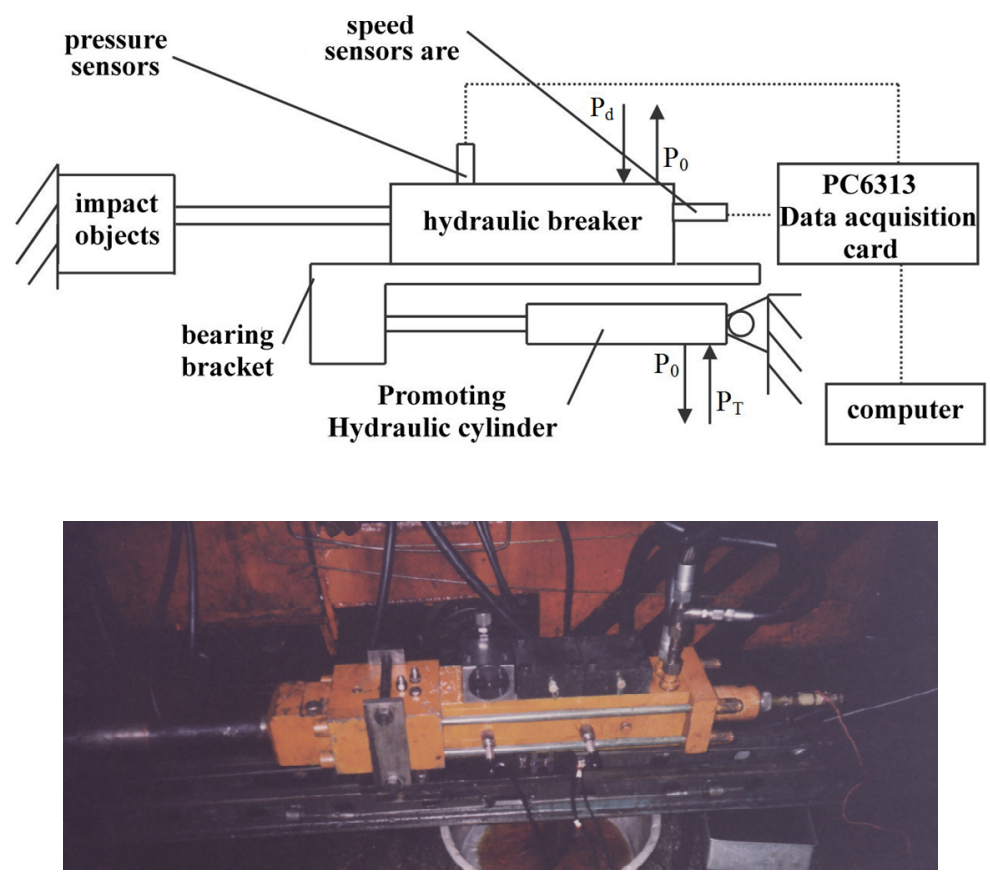

Figure 3. Experiment model photograph of the pressure feedback hydraulic breaker

We tested and researched the two aspects of the technical performance of the experimental model machine:

- When the flow remains unchanged, adjust the feedback pressure and measures a group of experimental curves and work parameters. See Figure 4 and Table 1 for the details. The $V_{1}$ on the figure shows the movement speed to impact the piston.

The main working parameters of the breaker can be calculated according to the experimental data, see Table 1 . 


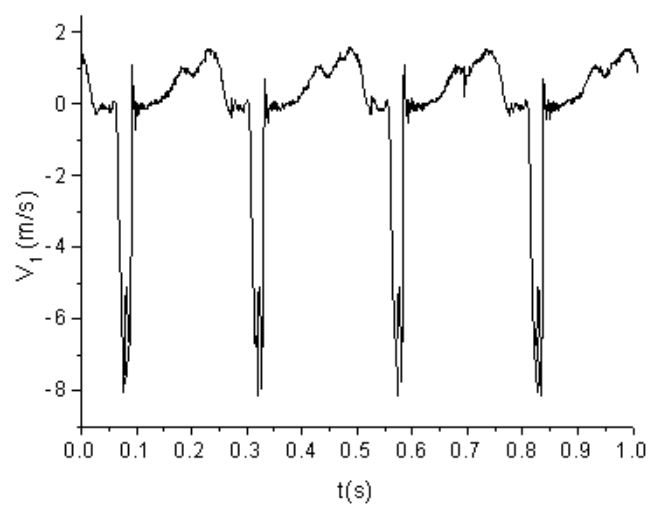

(a) $\mathrm{P}^{*}=9 \mathrm{Mpa}$

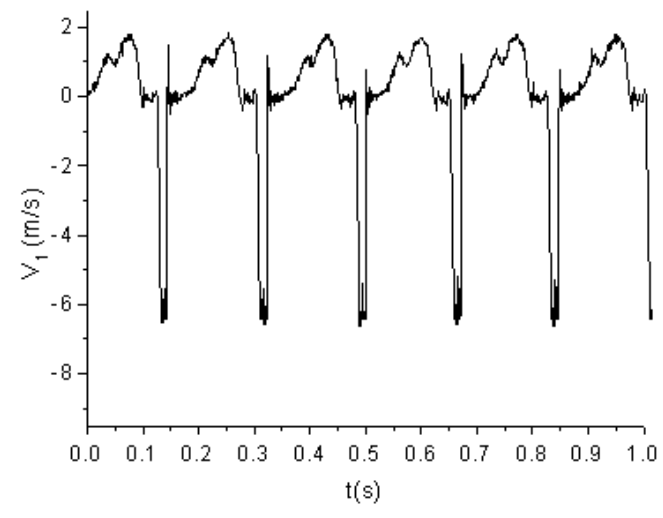

(b) $\mathrm{P}^{*}=15 \mathrm{MPa}$

Figure 4. Velocity curve of the hydraulic breaker (when forerunner control valve' regulate pressure was changed, oil flow of pump $\mathrm{Q}_{\mathrm{d}}=401 / \mathrm{min}$ )

Table 1. The main working parameters of the breaker

\begin{tabular}{lcccccc}
\hline Setup of pressure $\mathrm{P}^{*}(\mathrm{MPa})$ & 9 & 11 & 12 & 13 & 14 & 15 \\
\hline impact end speed $\mathrm{V}_{\mathrm{c}}(\mathrm{m} / \mathrm{s})$ & 6.45 & 7.03 & 7.23 & 7.68 & 7.87 & 8.08 \\
impact energy E $(\mathrm{J})$ & 328.66 & 390.43 & 412.96 & 465.960 & 489.30 & 515.76 \\
impact frequency f $(1 / \mathrm{min})$ & 318.26 & 317.76 & 317.28 & 316.73 & 316.15 & 315.12 \\
\hline
\end{tabular}

After analyzing the measurements, we can obtain the following conclusions:

- If the oil flow of the oil pump in the impact system and the initial charge pressure in the accumulator of hydraulic breaker are fixed, by changing the setup pressure in the breaker's pilot valve, the impact energy of the hydraulic breaker can be adjusted. If the setup pressure is higher, then the impact energy is larger. Whereas, the impact energy is less. However, the impact frequency doesn't change too much.

- If the setup pressure of the pilot remains unchanged, with the change of flow $\mathrm{Q}_{\mathrm{d}}$ in the oil pump, we measured a group of experimental curves and working parameters, see Figure 5 and Table 2 for the details.

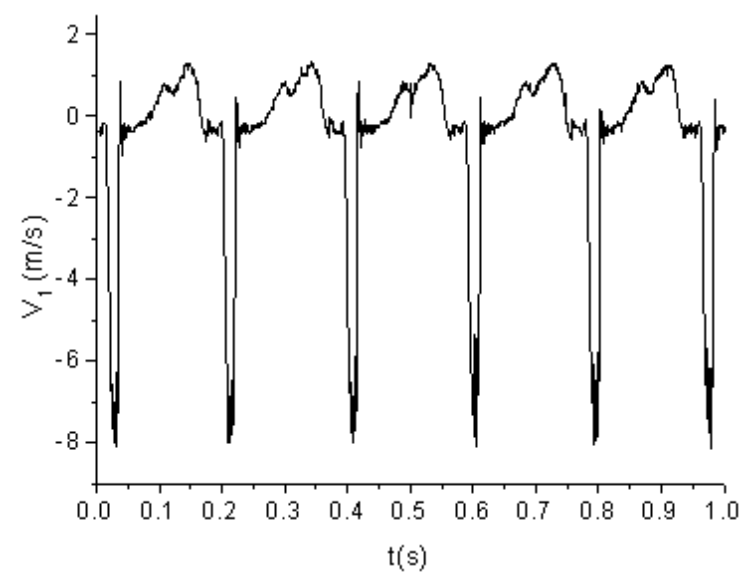

(a) $Q_{d}=15(1 / \mathrm{min})$

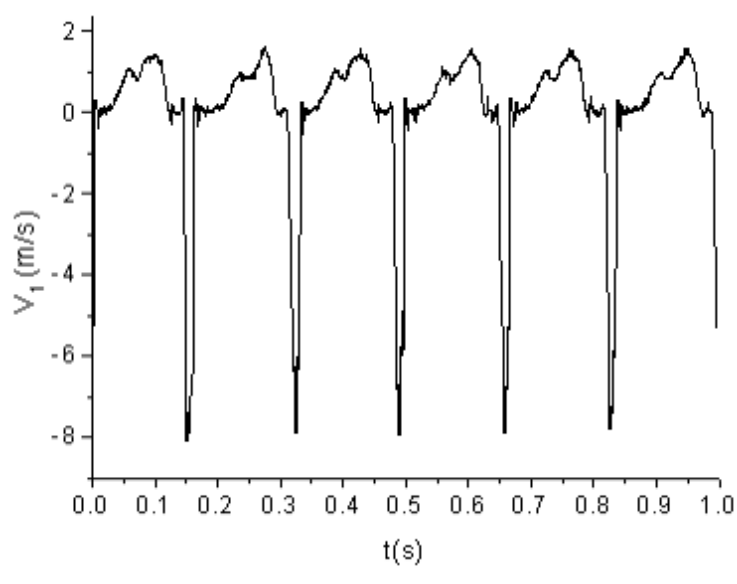

(b) $Q_{d}=40 \quad(1 / \mathrm{min})$

Figure 5. Capability curve of the hydraulic breaker (when oil flow of pump was changed, forerunner control valve' regulate pressure $\mathrm{p}=15 \mathrm{Mpa}$ ) 
The main working parameters of the breaker can be calculated according to the experimental data, see Table 2 .

Table 2. The main working parameters of the breaker

\begin{tabular}{lcccccc}
\hline Flow $\mathrm{Q}_{\mathrm{d}}(\mathrm{l} / \mathrm{min})$ & 15 & 20 & 25 & 30 & 35 & 40 \\
\hline impact end speed $\mathrm{V}_{\mathrm{c}}(\mathrm{m} / \mathrm{s})$ & 8.013 & 8.028 & 8.043 & 8.058 & 8.073 & 8.088 \\
impact energy $\mathrm{E}(\mathrm{J})$ & 507.24 & 509.15 & 511.05 & 512.96 & 514.87 & 516.78 \\
impact frequency $\mathrm{f}(1 / \mathrm{min})$ & 230.77 & 247.56 & 260.87 & 273.52 & 285.71 & 315.12 \\
\hline
\end{tabular}

After analyzing the measurements, we can obtain the following conclusions:

- On condition that other work parameters of the system remain unchanged, by changing the breaker system's pressure $\mathrm{P}^{*}$, we can adjust the impact energy of the breaker. The pressure of the system is larger and then the piston's impact energy is higher, vice versa. However, the impact frequency basically remains unchanged.

- On condition that other work parameters of the system remain unchanged, by changing the breaker system's oil flow $\mathrm{Q}_{\mathrm{d}}$, we can adjust the impact frequency of the breaker. The oil flow of the system is larger and then the piston's impact frequency is higher, vice versa. However, the impact energy basically remains unchanged.

- Since the new type hydraulic breaker also can obtain very high impact energy at the small flow, which indicates the small installed capacity can obtain large impact energy.

\section{Conclusions}

The stroke feedback principle is widely used for the traditional hydraulic breaker. Following the flow characteristic operation, its impact energy (E) and frequency (f) increase and reduce synchronously, which can't meet the requirement of adjusting and reasonable matching the output parameters of $E$ and $f$ so as to adapt to the changing working conditions. Based upon the pressure feedback principle and breaking through the shortcomings of the traditional hydraulic breaker, we renovated and developed the full hydraulic breaker with independent stepless frequency and strike energy adjusting. It will also end the working method of constant strike energy, and enter into a new development stage of the impact energy (E) and frequency (f) being adjusted independently and steplessly. Owning independent intellectual property, the new type hydraulic breaker can further meet the requirement of operation conditions with wider application scope, higher working efficiency, lower production cost and stronger market competitive power .

\section{Acknowledgements}

The author wishes to thank the China National Natural Science Foundation Project $(50,975,169)$ and China Shanghai University Knowledge Innovation Engineering (085 Engineering) Project (JZ0901) for providing research fund and all colleagues who previously provide technical support.

\section{References}

Yang, G. P. (2002).The research on the new type hydraulic crushing hammer's pilot type orifice valve. China Mechanical Engineering, 13(10), 891-893.

Yang, G. P. (2006). Research of a full hydraulic pressure hydraulic impactor with strike energy and frequency adjusted independently. Journal of Hunan University of Science and Technology (Naural Science Edition), $21(1), 25-28$.

Yang, G. P. (2006). Research on Computer Simulation for a New Pilot Type Hydraulic Impactor System. Mechanical Science and Technolgy, 25(2), 233-237.

Yang, G. P., \& Liang, C. P. (2010). Research on the New Hydraulic Impactor Control System. 2010 international conference on measuring technology and mechatronics automation, $207-210$.

Yang, G. P., Chen, B. J., \& Gao, J. H. (2011). Improved design and analysis of hydraulic impact hammer based on virtual prototype technology. Applied Mechanics and Materials (Measuring Technology and Mechatronics Automation), 48-49, 607-610. http://dx.doi.org/10.4028/www.scientific.net/AMM.48-49.607

Yang, G. P., Gao, J. H., \& Chen, B. J. (2011). Computer Simulation of Controlled Hydraulic Impactor System. Advanced Materials Research (Materials Science and Engineering), 179-180, 122-127. http://dx.doi.org/10.4028/www.scientific.net/AMR.179-180.122 
Yang, G. P., Yang, X. B., \& Liu, Z. J. (2002). The application of MATLAB language on the emulation of hydraulic impact . Road machinery \& construction mechanization, 19, 5-7.

Yang, G. P., Chu, F. L., Long, G. J., \& Liu, Z. J. (2003). The research on self-adaptation control of hydraulic crushing hammer's impact damper. China Mechanical Engineering, 14(2), 1062-1065. 